\title{
OR14-V-Uncertainty-PD2La Uncertainty Quantification for Nuclear Safeguards and Nondestructive Assay Final Report
}

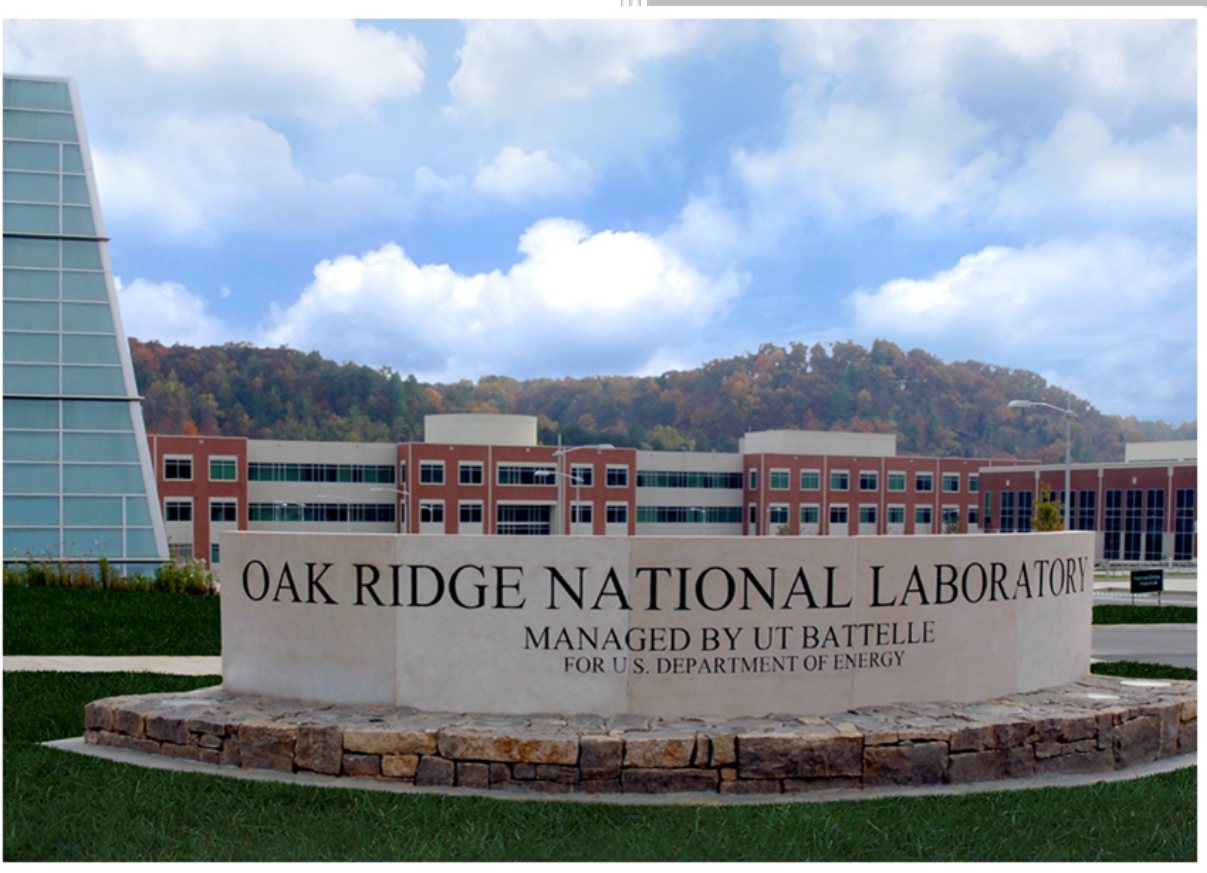

Stephen Croft

Andrew Nicholson

August 2017

Approved for public release. Distribution is unlimited. 


\section{DOCUMENT AVAILABILITY}

Reports produced after January 1, 1996, are generally available free via US Department of Energy (DOE) SciTech Connect.

Website http://www.osti.gov/scitech/

Reports produced before January 1, 1996, may be purchased by members of the public from the following source:

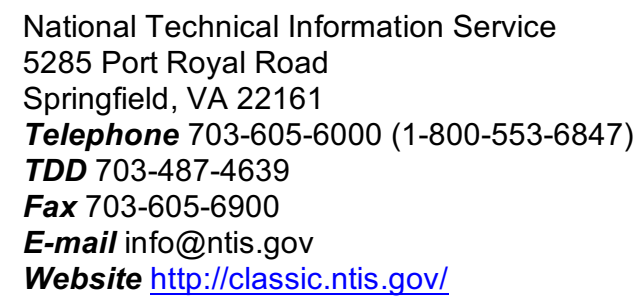

Reports are available to DOE employees, DOE contractors, Energy Technology Data Exchange representatives, and International Nuclear Information System representatives from the following source:

Office of Scientific and Technical Information

PO Box 62

Oak Ridge, TN 37831

Telephone 865-576-8401

Fax 865-576-5728

E-mail reports@osti.gov

Website http://www.osti.gov/contact.html

This report was prepared as an account of work sponsored by an agency of the United States Government. Neither the United States Government nor any agency thereof, nor any of their employees, makes any warranty, express or implied, or assumes any legal liability or responsibility for the accuracy, completeness, or usefulness of any information, apparatus, product, or process disclosed, or represents that its use would not infringe privately owned rights. Reference herein to any specific commercial product, process, or service by trade name, trademark, manufacturer, or otherwise, does not necessarily constitute or imply its endorsement, recommendation, or favoring by the United States Government or any agency thereof. The views and opinions of authors expressed herein do not necessarily state or reflect those of the United States Government or any agency thereof. 
Nuclear Security and Isotope Technology Division

\title{
OR14-V-Uncertainty-PD2La Uncertainty Quantification for Nuclear Safeguards and
} Nondestructive Assay Final Report

\author{
Stephen Croft \\ Andrew Nicholson \\ Tom Burr \\ Ken Jarman \\ Robert McElroy \\ Adam Shephard \\ Andrea Favalli \\ Daniela Henzlova \\ Brian Weaver
}

Date Published: July 2017

\author{
Prepared by \\ OAK RIDGE NATIONAL LABORATORY \\ Oak Ridge, TN 37831-6283 \\ managed by \\ UT-BATTELLE, LLC \\ for the \\ US DEPARTMENT OF ENERGY \\ under contract DE-AC05-00OR22725
}





\section{CONTENTS}

1. OVERVIEW PROJECT, INTRODUCTION, PUBLICATIONS, AND

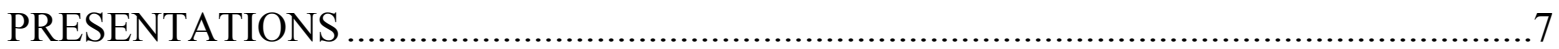

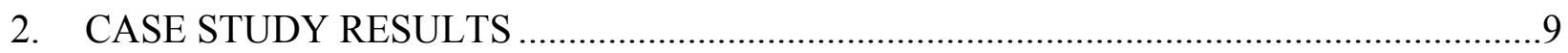

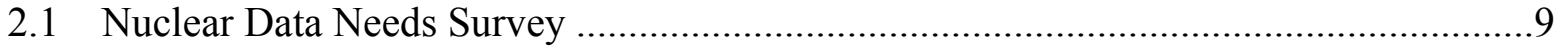

2.2 Uncertainty Quantification Workshop ……………................................................

2.3 Minimum Detectable Activity Definition .............................................................

2.4 Hybrid k-edge Densitometry Uncertainty Quantification ..............................................11

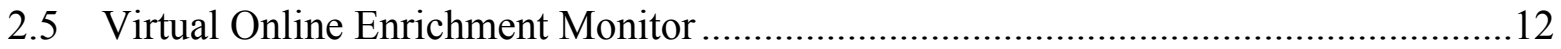

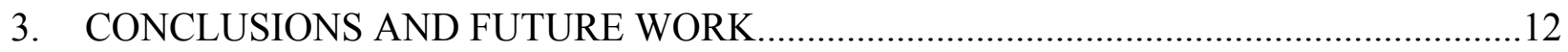

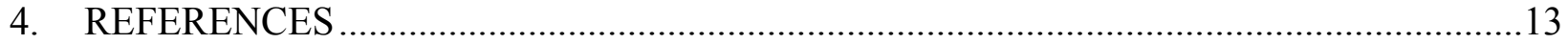





\section{OVERVIEW PROJECT, INTRODUCTION, PUBLICATIONS, AND PRESENTATIONS}

The various methods of nondestructive assay (NDA) of special nuclear material (SNM) have applications in nuclear nonproliferation, including detection and identification of illicit SNM at border crossings and quantifying SNM at nuclear facilities for safeguards. No assay method is complete without "error bars," which provide one way of expressing confidence in the assay result. Consequently, NDA specialists typically provide error bars and also partition total uncertainty into "random" and "systematic" components so that, for example, an error bar can be developed for the total mass estimate in multiple items. Uncertainty Quantification (UQ) for NDA has always been important, but it is recognized that greater rigor is needed and achievable using modern statistical methods [1].

From a safeguards perspective, poorly derived UQ can mask trends in material balances, which otherwise should be investigated. Alternatively, poor UQ can mistakenly indicate large amounts of material unaccounted for (MUF), also referred to as Inventory Difference (ID), which can cause unnecessary investigations. Poor UQ leads to overdesigned systems that are wasteful, or needlessly supplemented to meet desired goals, and can lead to faulty decision-making. UQ in NDA for materials control and accountancy (MC\&A) is consequently widely understood to be of great importance, although it has been essentially dormant over the last two decades. Perhaps surprisingly, a thorough and implemented UQ does not exist even for such a basic and widely fielded technique as the ${ }^{235} \mathrm{U}$ Enrichment Meter Principle (EMP). As the complexity of the measurement system increases (e.g., installed joint use instruments deploying multiple correction algorithms and operated in unattended mode), the details of how uncertainties are generated and how reliable they are become even less clear. There is an urgent need to reinvigorate the field using modern methods to improve effectiveness and reduce the chance of incidents due to poor UQ.

OR14-V-Uncertainty-PD2La Uncertainty Quantification for Nuclear Safeguards and NonDestructive Assay brought modern methods of UQ into the NDA domain via a series of case studies. This was a venture project, led by ORNL (PI: Stephen Croft and Andrew Nicholson) with collaborators at PNNL (Ken Jarman) and LANL (Andrea Favalli, Tom Burr, Brian Weaver, and Daniela Henzlova). Below is a list of peer-reviewed publications and presentations produced over the course of the project.

Peer Reviewed Publications:

- T. Burr, S. Croft, and K. Jarman, "Uncertainty Quantification in Nondestructive Assay of Special Nuclear Material," Journal of Sensors, 267462 (2015)

- S. Croft, and T. Burr, "Calibration of Nondestructive Assay Instruments: an Application of Linear Regression and Propagation of Variance, Special Issue on Regression," Applied Mathematics 5, 785-798, (2014)

- K. Jarman, L. Smith, and M. Zalavadia, Uncertainty Quantification for Nuclear Safeguards and Non-Destructive Assay: Emulator Progress, PNNL-23695 (2014)

- A. Nicholson, S. Croft, and R. D. McElroy Jr., "K-Shell Fluorescence Yields and Their Uncertainties for Use in Hybrid K-Edge Densitometry," Radioanal. Nucl. Chem. (2016) 
- A. M. Shephard, A. Nicholson, and S. Croft, Enrichment Meter Dataset from HighResolution Gamma Spectroscopy Measurements of $U_{3} O_{8}$ Enrichment Standards and $U F_{6}$ Cylinder Wall Equivalents, ORNL/TM-2015/370 (2015)

- T. Burr, S. Croft, T. Krieger, K. Martin, C. Norman, and S. Walsh, "Uncertainty quantification for radiation measurements: Bottom-up error variance estimation using calibration information," Applied Radiation and Isotopes, 108, 49-57 (2016)

- S. Croft, T. Burr, A. Favalli, and A. Nicholson, "Analysis of calibration data for the uranium active neutron coincidence counting collar with attention to errors in the measured neutron coincidence rate," Nuclear Instruments and Methods in Physics Research Section A, Online (2015)

Presentations:

- R. Bahran, S. Croft, J. Hutchinson, M. Smith, and A. Sood, "A survey of nuclear data deficiencies affecting nuclear non-proliferation," Proceedings of the $55^{\text {th }}$ Annual Meeting of the Institute of Nuclear Materials Management, July 20-24, 2014, Atlanta, Georgia, USA

- S. Croft. T. Burr, K. Jarman, R. McElroy, A. Nicholson, and A. Shephard, "Uncertainty Quantification for Safeguards Measurements," Symposium on International Safeguards, October 20-24, 2014, Vienna, Austria

- S. Croft, T. Burr, K. D. Jarman, J. M. Kirkpatrick, and R. Venkataraman, "Exact propagation of variance and confidence interval calculations," Proceedings of the $55^{\text {th }}$ Annual Meeting of the Institute of Nuclear Materials Management, July 20-24, 2014, Atlanta, Georgia, USA

- T. Burr, A. Hoover, M. Rabin, and S. Croft, "Exploring the impact of nuclear data uncertainties in ultra-high resolution gamma spectroscopy for isotopic analysis using approximate Bayesian computation," Proceedings of the $55^{\text {th }}$ Annual Meeting of the Institute of Nuclear Materials Management, July 20-24, 2014, Atlanta, Georgia, USA

- J. M. Kirkpatrick, S. Croft, T. Burr, M. Soriano, and R. Venkataraman, "Fundamental considerations in uncertainty analysis for NDA measurements," Proceedings of the $55^{\text {th }}$ Annual Meeting of the Institute of Nuclear Materials Management, July 20-24, 2014, Atlanta, Georgia, USA

- S. Croft. T. Burr, K. Jarman, R. McElroy, A. Nicholson, and A. Shephard, "Uncertainty Quantification for Safeguards Measurements," Symposium on International Safeguards, October 20-24, 2014, Vienna, Austria

- R. Venkataraman, S. C. Smith, J. Kirkpatrick, and S. Croft, "Minimum detectable activity for tomographic gamma scanning system," WM2015 Waste Management Conference, March 15-19, 2015, Phoenix, Arizona, USA

- K. D. Jarman, L. E. Smith, R. S. Wittman, M. A. Zalavadia, S. Croft, and T. Burr, "Uncertainty Analysis for Non-Destructive Assay with Application to An On-Line Enrichment Monitor," Joint International Conference on M\&C, SNA and MC, April 1923, 2015, Nashville, TN, USA

- A. Nicholson, S. Croft, and R. D. McElroy Jr., "K-Shell Fluorescence Yields and Their Uncertainties for Use in Hybrid K-Edge Densitometry," Methods and Applications of Radioanalytical Chemistry (MARC) Conference, March 25-30, 2015, Kailua-Kona, Hawaii, USA 
- A. Nicholson, S. Croft, and R. D. McElroy Jr., "Sensitivity Analysis of the LargeVolume Active Well Coincidence Counter to the ${ }^{252} \mathrm{Cf}$ Spectrum," Proceedings of the $56^{\text {th }}$ INMM Annual Meeting, Indian Wells, CA (July 2015)

- S. Croft, A. Nicholson, J. M. Kirkpatrick, and T. Burr, "The Influence of Correlated Variance Structure in Relative Isotopic Abundances on Nondestructive Assay Results," Proceedings of the $56^{\text {th }}$ INMM Annual Meeting, Indian Wells, CA, July 12-16, 2015

- S. Croft, R. D. McElroy, A. Nicholson, and T. Guzzardo, "Mass Attenuation Coefficient (Photo-Electric Cross Section) Data for Hybrid K-Edge Densitometry: Natural Line Width \& Lifetime Relation," Proceedings of the $56^{\text {th }}$ INMM Annual Meeting, Indian Wells, CA, July 12-16, 2015

- S. Croft, A. Nicholson, A. M. Shephard, and T. Sampson, "Uranium Enrichment Measurements Using the Enrichment Meter Principle," Proceedings of the $56^{\text {th }}$ INMM Annual Meeting, Indian Wells, CA, July 12-16 2015

- S. Croft, S. Cleveland, and A. Nicholson, "Calculation of the ${ }^{240} \mathrm{Pu}$-Effective Coefficients for Neutron Correlation Counting: Evaluation," Proceedings of the $56^{\text {th }}$ INMM Annual Meeting, Indian Wells, CA, July 12-16, 2015

- A. Nicholson, S. Croft, and G. V. Walford, "A Calibration Study for Holdup Measurements," $56^{\text {th }}$ INMM Annual Meeting, Indian Wells, CA, July 12-16, 2015

- A. Nicholson, S. Croft, and R. D. McElroy Jr., "Sensitivity Analysis of the LargeVolume Active Well Coincidence Counter to the ${ }^{252} \mathrm{Cf}$ Spectrum," Proceedings of the $56^{\text {th }}$ INMM Annual Meeting, Indian Wells, CA, July 12-16, 2015

- R. Vogt, A. Nicholson, J. Randrup, I. Gauld, and S. Croft, "Uncertainty Quantification with the Event-by-Event Fission Model FREYA," Proceedings of the 1st ANS Advances in Nuclear Nonproliferation Technology and Policy, Santa Fe, NM, 2016

- S. Croft, A. Nicholson, D. Henzlova, and A. Favalli, "Representing the Uncertainty Structure of the Factorial Moments of ${ }^{252} \mathrm{Cf}$ and ${ }^{238 ; 240 ; 242} \mathrm{Pu}$," 1st ANS Advances in Nuclear Nonproliferation Technology and Policy, Santa Fe, NM, 2016

- B. Weaver, A. Favalli, D. Henzlova, "Plutonium Mass Determination by Neutron Counting," Proceedings of the 1st ANS Advances in Nuclear Nonproliferation Technology and Policy, Santa Fe, NM 2016

\section{CASE STUDY RESULTS}

Below is a short description of results from many of the case studies explored in this project. More information can be found in cited references.

\subsection{NUCLEAR DATA NEEDS SURVEY}

A general survey of nuclear data deficiencies that was administered across various academic and research institutions was presented at the annual meeting of the Institute for Nuclear Materials Management in 2014; see Ref. [2]. The purpose of the survey was to identify the most significant nuclear data deficiencies affecting applications in nuclear nonproliferation. The most widely reported general issues reported in the survey were related to correlated particle emissions from fissile nuclear material, fission product data, neutron total and partial cross sections of various isotopes, and $(\alpha, n)$ yields from light elements. A quantitative summary of the results is presented in Figure 1. 


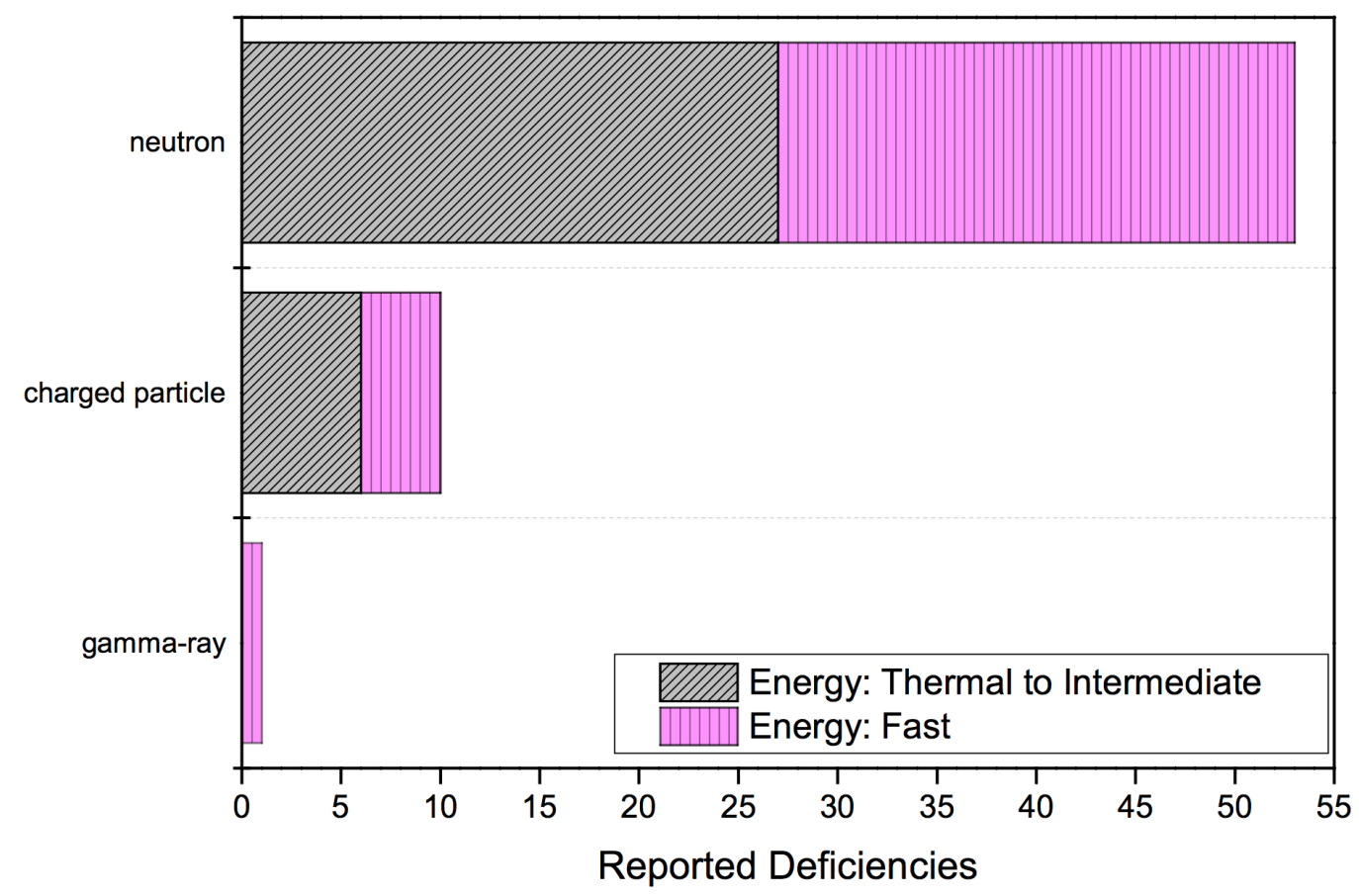

Figure 1. A global overview of the survey responses that were obtained from a self-administered survey on the most significant nuclear data deficiencies; see Ref. [2].

\subsection{UNCERTAINTY QUANTIFICATION WORKSHOP}

A successful workshop on UQ for NDA was held after the American Nuclear Society (ANS) conference on Advances in Nuclear Nonproliferation Technology and Policy held September 28-30, 2016, in Santa Fe, New Mexico. Twelve papers were presented along with two breakout sessions to discuss trends and needs in UQ. Hosted and facilitated by the NA-22 UQ team, the workshop was attended by 43 participants. A suitable forum to extend this engagement may be the INMM-2017 meeting. The team presented several relevant papers; see Refs. [3-5]. A separate, more detailed report can be found on WebPMIS.

\subsection{MINIMUM DETECTABLE ACTIVITY DEFINITION}

The project team collaborated with Ram Ventataraman (formally Canberra now ORNL) on a study of the minimum detectable activity (MDA) for the Tomographic Gamma-Ray Scanner (TGS). This work was presented at the WM2015 Waste Management Conference and is included in the proceedings [6]. The MDA is an important figure of merit used to determine if an assay technique is appropriate for a measurement scenario.

In this work, the Currie formalism was applied to a safeguards gamma-ray imaging system. The TGS assay technique uses a combination of gamma-ray transmission (to determine detection efficiency) and passive gamma-ray detection (to determine the presence of sources). A MDA figure of merit, based on the gamma-ray background and energy-dependent detection efficiency, 
was determined for three radioactive sources: ${ }^{133} \mathrm{Ba},{ }^{60} \mathrm{Co}$, and ${ }^{137} \mathrm{Cs}$. The MDAs of these sources at varying source strengths were then compared. Figure 2 shows transmission and passive measurements taken for three source strengths of ${ }^{133} \mathrm{Ba}$. Figure 2 (a) has a source below the calculated MDA, $0.46 \mu \mathrm{Ci}$. From the image, it is impossible to differentiate the source from the background. On the other hand, in Figures 2 (b) and (c), the source can be located above the calculated MDA.

This study boosts confidence in the Currie method and its application to an imaging system, in this case the TGS, to provide guidance as to which samples this assay technique can be used successfully.

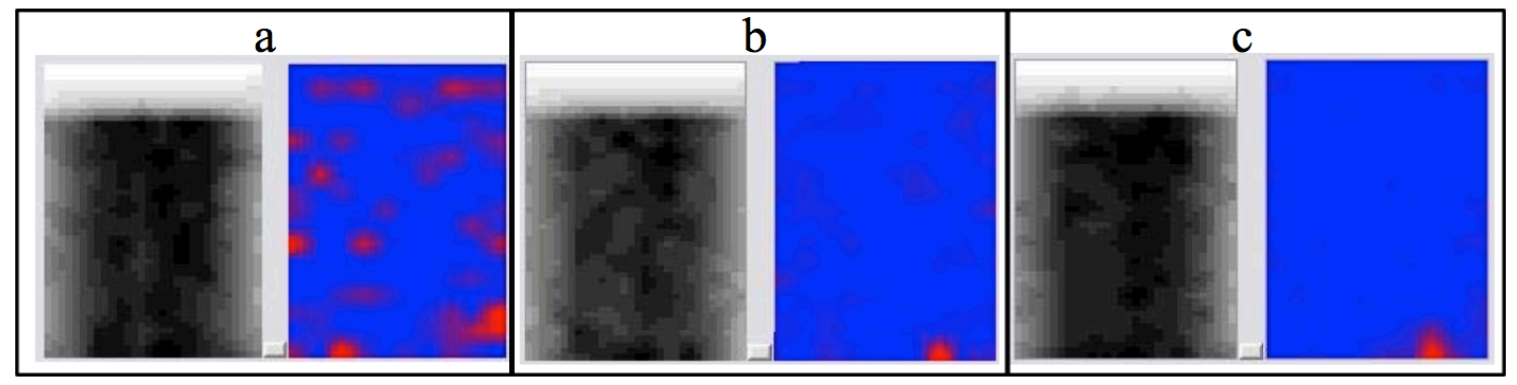

Figure 2. Transmission (left) and passive (right) measurements on a 5 gallon pail filled with a walnut matrix and ${ }^{133} \mathrm{Ba}$ source placed at the bottom of the pail: (a) $0.24 \mu \mathrm{Ci}$, (b) $0.48 \mu \mathrm{Ci}$, and (c) $0.68 \mu \mathrm{Ci}$; see Ref [6].

\subsection{HYBRID K-EDGE DENSITOMETRY UNCERTAINTY QUANTIFICATION}

The team conducted a study of the use of a bootstrapping method to determine K-shell fluorescence yield uncertainties for use in physics-based models of Hybrid K-Edge Densitometry (HKED). This work was present at the MARCX conference and submitted for publication to the Journal of Radioanalytical Chemistry [7]. The probability of fluorescence after the ionization of an electron is called a fluorescence yield $\left(\omega_{\mathrm{K}}\right)$. HKED is a safeguards assay technique that combines a transmission measurement with a X-ray fluorescence measurement to determine concentrations of $[\mathrm{U}]$ and $[\mathrm{Pu}]$ in liquid samples (typically in nuclear reprocessing facilities). The concentration of $[\mathrm{U}]$ is determined via the transmission measurement and the relative concentration of $[\mathrm{Pu}] /[\mathrm{U}]$ is determined in the fluorescence measurement. $[\mathrm{Pu}]$ is hard to measure in the transmission measurement because it typically exists in much lower concentrations in the sample compared to [U]. Understanding uncertainties in the fluorescence yields of [U] and [Pu], and their covariance, is important to understand uncertainties in physics-based models for this technique.

In the current literature, uncertainty information on fluorescence yield data is sparse and, if it exists, lacks covariance information between fluorescence yields as a function of atomic number $\mathrm{Z}$. To solve this problem, the team collected data from many experimental reports for the fluorescence yield for $11 \leq Z \leq 99$ published between 1978 and 2011. A bootstrapping method, generating synthetic datasets using fluoresce yield means and uncertainties, was used with an empirical fit function to extract uncertainty (and covariance) data for the fluorescence yields for all Z. This method can not only produce fluorescence yield values and uncertainties but also 
histograms of the underlying distributions. This is helpful because the distribution is not normal, instead taking some other shape. This data evaluation was used to determine the uncertainties in the fluorescence yield ratio $\mathrm{Pu} / \mathrm{U}$, which is shown in Table 1 with references to other experiments. The covariance terms generated by the bootstrapping method were found to be large compared to the uncertainties in the fluorescence yields for $\mathrm{U}$ and $\mathrm{Pu}$ and reduced the total uncertainty in the ratio of fluorescence yields needed for models in HKED.

Table 1. List of fluorescence yield values from the literature. The results produced in this work, and in Kahoul, Hubbell, Bambynek and Krause, are due to curve-fitting to experimental data. The value from Chen comes from relativistic quantum mechanical calculations. For more information, see Ref. [7]

\begin{tabular}{|c|c|c|c|c|c|c|c|c|c|}
\hline Source & \multicolumn{3}{|c|}{$\omega_{\mathrm{k}}(92)$} & \multicolumn{3}{c|}{$\omega_{\mathrm{k}}(94)$} & \multicolumn{3}{c|}{$\omega_{\mathrm{k}}(94) / \omega_{\mathrm{k}}(92)$} \\
\hline This Work & 0.9727 & \pm & 0.0036 & 0.9736 & \pm & 0.0037 & 1.0009 & \pm & 0.0001 \\
\hline Kahoul (2012) & 0.9698 & \pm & 0.001 & 0.9714 & \pm & 0.002 & 1.0016 & \pm & - \\
\hline Hubbell (1994) & - & \pm & - & 0.969 & \pm & - & - & \pm & - \\
\hline Bambynek (1984) & 0.9701 & \pm & - & 0.971 & \pm & - & 1.0009 & \pm & - \\
\hline Chen (1980) & 0.97 & \pm & - & - & \pm & - & - & \pm & - \\
\hline Krause (1979) & 0.972 & \pm & - & 0.973 & \pm & - & 1.001 & \pm & - \\
\hline
\end{tabular}

\subsection{VIRTUAL ONLINE ENRICHMENT MONITOR}

See Uncertainties for OLEM, a separate report in WebPMIS.

\section{CONCLUSIONS AND FUTURE WORK}

In the physical sciences, estimated quantities, for example, quantities derived from a combination of measured values, parameters, and theoretical models, are incomplete without a justifiable uncertainty statement suitable for the user of the information, explaining the confidence which may be placed in the estimate.

NDA forms one piece, but a very important one, of an integrated safeguards approach for special nuclear materials in a facility and country. Ultimately, material accountability depends on the quality of measurement science. Consequently, understanding how measurements are performed and how measurement systems perform underpins this work. Justifiable uncertainty funding is needed to support every result. The process of creating estimates is often complex and more time-consuming than generating the result itself. For example, UQ for radiation metrology has been poorly documented, received too little attention, and consistently given overly optimistic estimates of the uncertainty (often due to neglected sources of error, which we aim to address using a "data generator"). An examination of how safeguards tools implement and propagate measurement uncertainty in light of current thinking is the focus of this work. Improving UQ can also improve the overall system of measurement and improve effective use of resources.

Moving forward, the team would like to continue engagement with the NDA community on UQ through continued support of annual workshops and production of best practice and process guides. 


\section{REFERENCES}

[1] S. Croft and T. Burr, "Calibration of Nondestructive Assay Instruments: an Application of Linear Regression and Propagation of Variance, Special Issue on Regression," Applied Mathematics 5, 785-798 (2014)

[2] R. Bahran, S. Croft, J. Hutchinson, M. Smith, and A. Sood, “A survey of nuclear data deficiencies affecting nuclear non-proliferation," Proceedings of the $55^{\text {th }}$ Annual Meeting of the Institute of Nuclear Materials Management, July 20-24, 2014, Atlanta, Georgia, USA

[3] R. Vogt, A. Nicholson, J. Randrup, I. Gauld, and S. Croft, "Uncertainty Quantification with the Event-by-Event Fission Model FREYA," Proceedings of the 1st ANS Advances in Nuclear Nonproliferation Technology and Policy, Santa Fe, NM 2016

[4] S. Croft, A. Nicholson, D. Henzlova, and A. Favalli, "Representing the Uncertainty Structure of the Factorial Moments of ${ }^{252} \mathrm{Cf}$ and ${ }^{238 ; 240 ; 242} \mathrm{Pu}$," Proceedings of the 1st ANS Advances in Nuclear Nonproliferation Technology and Policy, Santa Fe, NM 2016

[5] B. Weaver, A. Favalli, and D. Henzlova, "Plutonium Mass Determination by Neutron Counting," Proceedings of the 1st ANS Advances in Nuclear Nonproliferation Technology and Policy, Santa Fe, NM 2016

[6] R. Venkataraman, S.C. Smith, J. Kirkpatrick, and S. Croft, "Minimum detectable activity for tomographic gamma scanning system," WM2015 Waste Management Conference, March 15-19, 2015, Phoenix, Arizona, USA

[7] A. Nicholson, S. Croft, and R. D. McElroy Jr., "K-Shell Fluorescence Yields and Their Uncertainties for Use in Hybrid K-Edge Densitometry," Radioanal. Nucl. Chem. (2016) 